\title{
PENGARUH JUS BELIMBING TERHADAP PENURUNAN TEKANAN DARAH PADA PENDERITA HIPERTENSI \\ (Studi di RT 05 Desa Pangkut Kecamatan Arut Utara Kabupaten Kotawaringin Barat Provinsi Kalimantan Tengah)
}

\author{
Cipta Nur Jihaddini ${ }^{1}$ Luluk Sulistiyono $^{2}$ Jon Persen Manik $^{3}$ \\ ${ }^{123}$ STIKes Borneo Cendekia Medika Pangkalan Bun \\ 1email : ciptanurjihad@gmail.com, 2email : 1uluksulistyono@gmail.com, 3emai : \\ jonpersenm@gmail.com
}

\begin{abstract}
ABSTRAK
Pendahuluan: Permasalahan hipertensi telah menjadi fenomena pemberitaan yang telah menjadi salah satu masalah teratas di Indonesia. Hipertensi sebagai salah satu penyakit yang sering timbul di masyarakat, apabila tidak dikendalikan dengan baik akan menimbulkan kerusakan pada target organ khususnya pada otak, jantung, ginjal, mata dan pembuluh darah perifer. Pembuatan penelitian bertujuan untuk menganalisis pengaruh jus belimbing terhadap penurunan tekanan darah pada penderita hipertensi.Metode penelitian: Metode penelitian dengan memakai enis penelitian one group pre test post tets desaign. Populasi pada penelitian ini sebanyak 105 orang. Teknik sampling yang di gunakan adalah slovin dengan hasil 51 responden. Instrumen penelitian menggunakan lembar observasi dimana pada setiap variabel penelitian. Hasil dan pembahasan:Hasil penelitian menjabarkan mengenai sebelum di beri perlakuan terapi jus belimbing sebagian besar dari responden mengalami hipertensi ringan sebanyak 28 orang $(54,9 \%)$. Dan di ketahui sesudah di berikanperlakuan terapi jus belimbing sebagian besar dari responden mengalami tekanan darah normal tinggi yaitu sebanyak 26 orang $(51,0 \%)$. Kesimpulan:Hasil penelitian menunjukan ada pengaruh jus belimbing terhadap penurunan tekanan darah dengan tingkat signifikan $P=0,000$.Kesimpulan penelitian yang didapatkan berupa ada pengaruh jus belimbing terhadap penurunan tekanan darah pada penderita. Saran: Peneliti menyarankan dalam menangani penurunan tekanan darah dapat diuapayakan dengan cara menggunakan jus belimbing karena sudah terbukti pegaruhnya secara komperhensif dalam bidang penelitian.
\end{abstract}

Kata kunci : Hipertensi, Jus belimbing, Tekanan darah

\section{INFLUENCE OF EFFECT ON GOODS BLOOD DECLINE ON HYPERTENSION PATIENTS}

(Study at RT 05 Village of Pungg Sub Arut Utara Regency of Kotawaringin Barat Province of Central Kalimantan)

\begin{abstract}
Introduction: The problem of hypertension has become a phenomenon might have become one of the top issues in Indonesia. Hypertension as one of a disease that often arise in the community, if not controlled properly will cause damage to target organs in particular on the brain, heart, kidneys, eyes and peripheral blood
\end{abstract}


vessels. The creation of research aims to analyze the influence of star fruit juice against a decrease in blood pressure in people with hypertension. Research methods: Research methods with enis research one group pre test post desaign tets. The population in this research as many as 105 people. The technique of sampling that is in use is the result of 51 respondents with slovin. Research instrument using the observation sheet where each variable in the study. Results and discussion: the research lays out about prior beri starfruit juice therapy treatment the majority of respondents experiencing mild hypertension as many as 28 people (54.9\%). And in the know after berikanperlakuan therapy in star fruit juice most of respondents experiencing high normal blood pressure that is as much as 26 people (51.0\%). Conclusion: Results of the study showed there was influence of star fruit juice against the drop in blood pressure with a significant level of $P$ $=0.000$. The conclusions obtained in the form of research there is the influence of star fruit juice against a decrease in blood pressure in people with. Suggestions: Researchers recommend in addressing the decline in blood pressure can be diuapayakan with how to use star fruit juice because of the proven pegaruhnya in comprehensiveresearchinthe field.

\section{Keywords: Hypertension, Star fruit juice, Blood pressure}

\section{PENDAHULUAN}

Permasalahan penyakit hipertensi menjadi suatu persoalan yang sampai sekarang masih mengalami peningkatan dan telah menelan banyak korban. Penyakit hipertensi telah menjadi permasalah fenomena penyakit keturunan yang bisa dikatakan sangat berbahaya.

Di dunia hampir 1 milyar orang atau 1 dari 4 orang dewasa menderita tekanan darah tinggi. Di Indonesia, mencapai $17-21 \%$ dari populasi penduduk dan kebanyakan tidak terdeteksi (Astawan, 2009, 21). Di tahun 2013 menunjukan secara nasional $25,8 \%$ penduduk indonesia menderita penyakit hipertensi (Kementrian kesehatan RI,2013, 34). Di tahun 2014 jumlah penduduk yang menderita penyakit hipertensi di arut utara sebanyak 938 jiwa Sedangkan survei puskesmas arut utara pada tahun 2016menunjukan bahwa jumlah penderita hipertensi di desa pangkut berjumlah 478 orang dan jumlah penderita hipertensi di rt 05 berjumlah 105 orang. Studi pendahuluan yang peneliti lakukan terhadap 10 reponden didapatkan hasil bahwa 4 responden dalam mengatasi masalah hipertens menggunakan obat antihipertensi dan 6 responden mengkonsumsi jamu.

Penyebab seseorang mengalai hipertensi salah satunya disebabnkan oleh kebiasaan merokok dan masih banyak lagi. Dampak yang telah timbul dari masalah hipertensi adalah timbulnya kejadian konpilikasi yang dapat menimulkan kematian dan mengganggu sistem organ lainnya dalam tubuh setiap individu (Kartikasari, 2012, 4).

Upaya dalam penanganan masalah hipertensi dapat dilakukan penatalaksanaan salah satunya memanfaatkan buah belimbing. Oleh karena itu, peneliti ingin melihat seberapa besar pengaruh jus belimbing terhadap penurunan tekanan darah, 
sehingga peneliti ingin mengambil judul pengaruh jus buah belimbing terhadap penurunan tekanan darah pada penderita hipertensi yang sampai saat ini masih memelukan tindakan pengkajian secara menyeluruh dengan menggunakan judul "pengaruh jus belimbing terhadap penurunan tekanan darah pada penderita hipertensi di rt 05 Desa Pangkut Kecamatan Arut Utara Kabupaten Kotawaringin Barat Provinsi Kalimantan Tengah.

\section{METODE PENELITIAN}

Penelitian yang dilakukan menggunakna jenis penelitian one group pre test post tets desaign, yaitu melakukan penelitian dengan cara melakukan tindakan pengukuran sebelum dan seudah diberikan perlakukaan (Notoatmodjo, 2010, 90).

Populasi adalah data yang menjadi bahan penelitaian secara keseluruhan. Semua penderita hipertensi di RT 05 kelurahan pangkut kecamatan arut utara kabupaten kotawaringin barat provinsi kalimantan tengah yang berjumlah 105 orang. Teknik sampling yang digunakan berupa metode simple random samplingdan didapatkan hasil sampel berjumlahsebanyak 51 orang(Sugiyono, 2012, 68).

Instrumen penelitian yang peneliti gunakan berupa lembar observasi paa variabel yang telah digunakna dalam penelitian ini.

\section{HASIL PENELITIAN}

\section{Data Umum}

Tabel 1 Distribusi Responden Berdasarkan Umur Responden Di Kelurahan Pangkut bulan Juni

\begin{tabular}{lccc}
\hline No & Umur & Jumlah & Persentase (\%) \\
1 & $>20$ & 19 & $37 \%$ \\
2 & $>45$ & 27 & $53 \%$ \\
3 & $>60$ & 5 & $10 \%$ \\
\hline \multicolumn{2}{c}{ Total } & 51 & $100 \%$ \\
\hline
\end{tabular}

Sumber : Data primer 2017

Dari tabel diatas didapatkan bahwa sebagian besar dari responden berusia $>45$ yang berjumlah 27 orang (53\%).

Tabel 2 Distribusi Responden Berdasarkan Jenis kelamin Responden Di Kelurahan Pangkut bulan Juni

\begin{tabular}{|c|c|c|c|}
\hline No & $\begin{array}{l}\text { Jenis } \\
\text { Kelamin }\end{array}$ & Jumlah & $\begin{array}{l}\text { Persentase } \\
(\%)\end{array}$ \\
\hline 1 & Laki-laki & 37 & $72 \%$ \\
\hline 2 & Perempuan & 14 & $28 \%$ \\
\hline & Total & 51 & $100 \%$ \\
\hline
\end{tabular}

Dari tabel diatas didapatkan bahwa sebagian besar dari responden berjenis kelamin laki-laki yang berjumlah 37orang ( $72 \%$ ).

Tabel 3 Distribusi Responden Berdasarkan Tingkat Pendidikan Responden Di Kelurahan Pangkut bulan Juni

\begin{tabular}{|c|c|c|c|}
\hline No & $\begin{array}{l}\text { Tingkat } \\
\text { pendidikan }\end{array}$ & Jumlah & $\begin{array}{l}\text { Persenta } \\
\text { se }(\%)\end{array}$ \\
\hline 1 & $\begin{array}{l}\text { Tidak } \\
\text { sekolah }\end{array}$ & 4 & $8 \%$ \\
\hline 2 & SD & 21 & $41 \%$ \\
\hline 3 & SMP & 14 & $27 \%$ \\
\hline 4 & SMA & 10 & $20 \%$ \\
\hline \multirow[t]{2}{*}{5} & Serjana & 2 & $2 \%$ \\
\hline & Total & 51 & $100 \%$ \\
\hline \multicolumn{4}{|c|}{ Sumber : Data primer 2017} \\
\hline \multicolumn{4}{|c|}{$\begin{array}{l}\text { Dari tabel diatas didapatkan bahwa } \\
\text { hampir dari setengahnyaresponden } \\
\text { berpendidikan SD yang berjumlah } \\
\text { 21orang }(41 \%) \text {. }\end{array}$} \\
\hline
\end{tabular}


Tabel 4 Distribusi Responden Berdasarkan PekerjaanResponden Di Kelurahan Pangkut bulan Juni
Dari tabel diatas didapatkan bahwa hampir dari setengah responden yang sering mengensumsi makanan asin, seperti ikan asin yang berjumlah

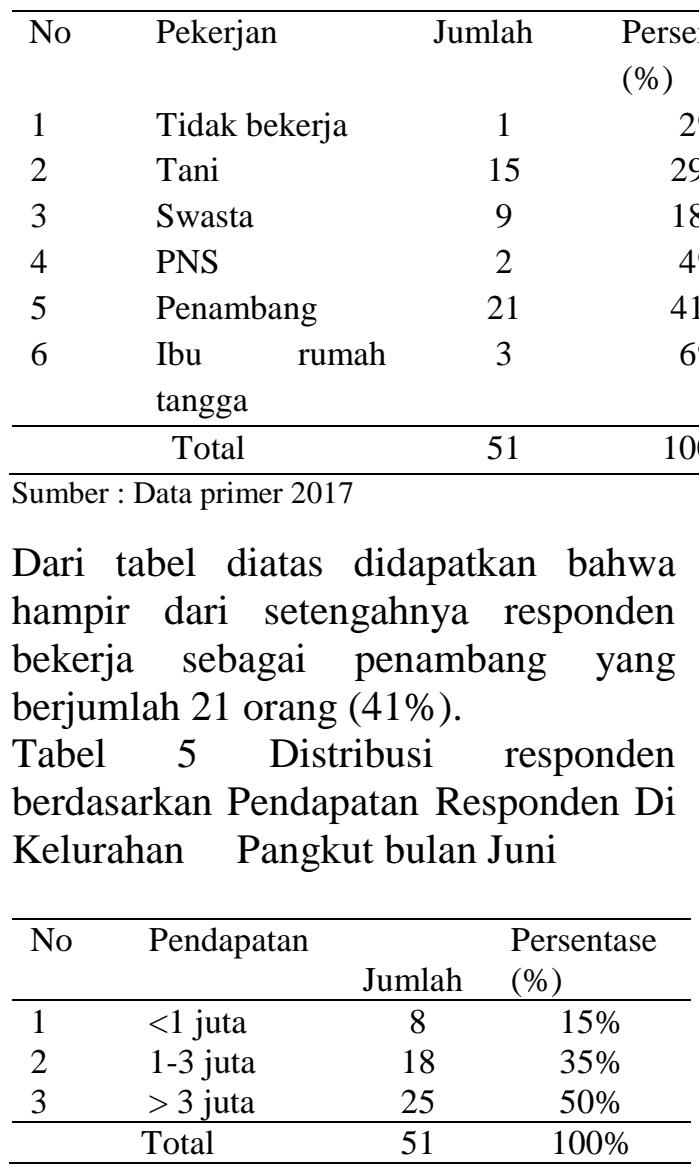

Sumber : Data primer 2017

Dari tabel diatas didapatkan bahwa setengah dari responden berpendapatan $>3$ juta yang berjumlah 25 orang $(50 \%)$.

Tabel 6 Distribusi responden berdasarkan Jenis Makanan yang sering dikonsumsi Di Kelurahan Pangkutbulan Juni

\begin{tabular}{llcc}
\hline No & $\begin{array}{l}\text { Jenis } \\
\text { makanan }\end{array}$ & Total & $\begin{array}{l}\text { Persentase } \\
(\%)\end{array}$ \\
\hline 1 & Ikan Laut & 5 & $10 \%$ \\
2 & Ayam & 7 & $14 \%$ \\
3 & Gorengan & 4 & $8 \%$ \\
4 & Ikan Asin & 24 & $47 \%$ \\
5 & Makanan & 6 & $11 \%$ \\
& Berserat & & $10 \%$ \\
6 & Makanan & 5 & $100 \%$ \\
\hline \multicolumn{5}{c}{ Pengawet } & 51 & \\
\hline Sumber : Data primer 2017 &
\end{tabular}

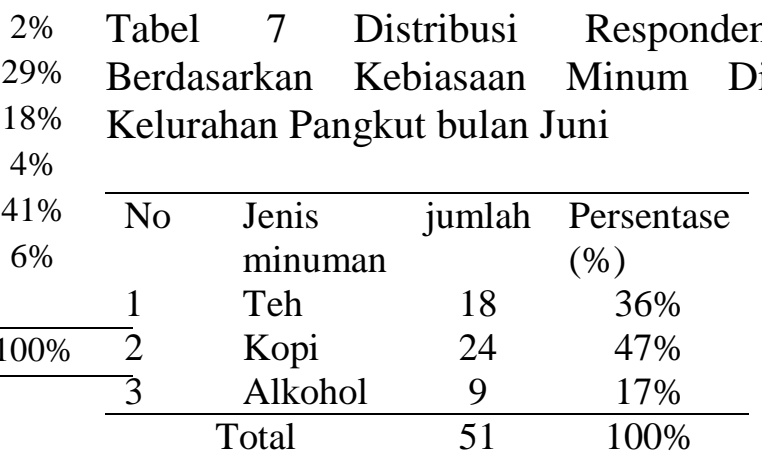

Sumber : Data primer 2017

Dari tabel diatas didapatkan bahwa hampir setengah responden kebiasaan minum kopi yang berjumlah 24orang (47\%).

Tabel 8 Distribusi Responden Berdasarkan Kebiasaan Merokok Di Kelurahan Pangkutbulan Juni

\begin{tabular}{llcc}
\hline No & $\begin{array}{l}\text { Kebiasaan } \\
\text { Merokok }\end{array}$ & Jumlah & $\begin{array}{l}\text { Persentase } \\
(\%)\end{array}$ \\
\hline 1 & Ya & 37 & $72 \%$ \\
2 & Tidak & 14 & $28 \%$ \\
\hline & Total & 51 & $100 \%$ \\
\hline Sumber : Data primer 2017 & &
\end{tabular}

Sumber : Data primer 2017

Dari tabel diatas didapatkan bahwa sebagian besar responden yang merokok berjumlah 37 orang (72\%).

\section{Data Khusus}

Tabel 9 Distribusi Responden Berdasarkan Tekanan Darah Sebelum di berikan jus belimbing Di Kelurahan Pangkut RT 05

\begin{tabular}{clcc}
\hline No & $\begin{array}{c}\text { Tekanan } \\
\text { darah }\end{array}$ & Jumlah & $\begin{array}{c}\text { Persentase } \\
\%\end{array}$ \\
\hline 1 & Optimal & 0 & $0 \%$ \\
2 & Normal & 0 & $0 \%$ \\
3 & $\begin{array}{l}\text { Normal } \\
\text { tinggi }\end{array}$ & 6 & $11,8 \%$ \\
4 & Hipertensi & 28 & $54,9 \%$
\end{tabular}




\begin{tabular}{|c|c|c|c|}
\hline \\
\hline 5 & $\begin{array}{l}\text { Hipertensi } \\
\text { sedang }\end{array}$ & 14 & $27,5 \%$ \\
\hline 6 & $\begin{array}{l}\text { Hipertensi } \\
\text { berat }\end{array}$ & 3 & $5,9 \%$ \\
\hline & Total & 51 & $100 \%$ \\
\hline \multicolumn{4}{|c|}{ Sumber : Data primer 2017} \\
\hline \multicolumn{4}{|c|}{$\begin{array}{l}\text { Dari tabel diatas didapatkan bahwa } \\
\text { sebagian besar dari responden mengalami } \\
\text { hipertensi ringan yaitu sebanyak 28orang } \\
(54,9 \%) \text {. }\end{array}$} \\
\hline
\end{tabular}

Tabel 10 Distribusi Responden Berdasarkan Tekanan Darah Sesudah Terapi jus belimbing Di Kelurahan Pangkut RT 05

\begin{tabular}{llcc}
\hline No & $\begin{array}{l}\text { Tekanan } \\
\text { Darah }\end{array}$ & Jumlah & $\begin{array}{l}\text { Persentase } \\
(\%)\end{array}$ \\
\hline 1 & Optimal & 5 & $9,8 \%$ \\
2 & Normal & 5 & $9,8 \%$ \\
3 & $\begin{array}{l}\text { Normal } \\
\text { Tinggi }\end{array}$ & 26 & $51,0 \%$ \\
4 & $\begin{array}{l}\text { Hipertensi } \\
\text { ringan }\end{array}$ & 13 & $25,5 \%$ \\
5 & $\begin{array}{l}\text { Hipertensi } \\
\text { sedang }\end{array}$ & 2 & $3,9 \%$ \\
6 & $\begin{array}{l}\text { Hipertensi } \\
\text { berat }\end{array}$ & 0 & $0 \%$ \\
\hline & Total & 51 & $100 \%$ \\
\hline
\end{tabular}

Dari tabel di atas didapatkan bahwa sebagian besar dari responden mengalami tekanan darah normal tinggi yaitu sebanyak 26 orang $(51,0 \%)$.

Tabel 11 Distribusi perbandingan tekanan darah sebelum dan sesudah di lakukan terapi jus belimbingselama 7 hari Terhadap penurunan tekanan darah di pangkut RT 05

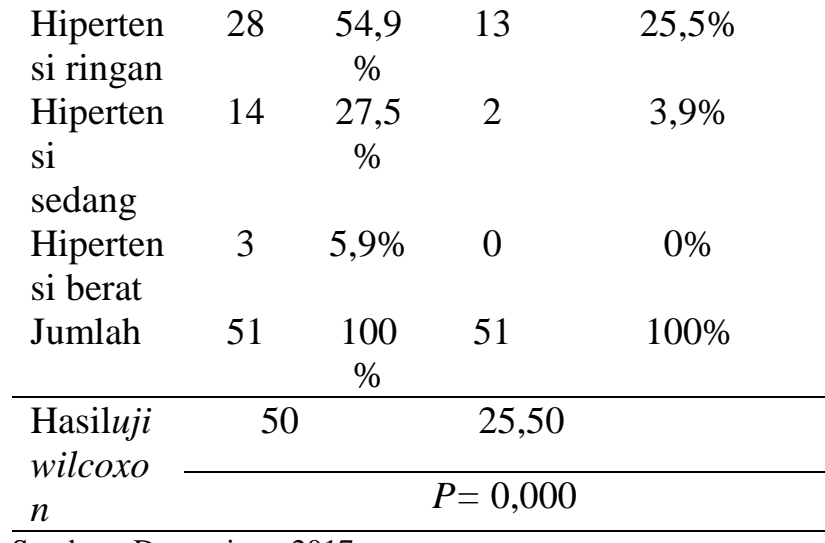

Sumber : Data primer 2017

Berdasarkan tabel 11 didapatkan bahwa sebagian besar responden sebelum diberikan terapi jus belimbing hipertensi ringan sebanyak 28 responden $(54,9 \%)$ dan setelah diberikan terapi jus belimbing selama 7 hari responden mengalami tekanan darah normal tinggi sebanyak 26 responden $(51,0 \%)$.

\section{PEMBAHASAN}

Tekanan darah sebelum dilakukan terapi jus belimbing

Menurut hasil penelitian yang didapatkan pada tabel 9 menyatakan bahwa tekanan darah sebelum di lakukan terapi jus belimbing diketahui sebagian besar dari responden mengalami hipertensi ringan yaitu sebanyak 28 orang $(54,9 \%)$.

Peneliti berpendapat dimana banyak faktor yang dapat mempengaruhi terjadi hipertensi salah satu adalah asupan makanan.

Hal ini di karenakan asupan makanan seperti ikan asin yang sering di konsumsi dapat di lihat pada tabel.6 hampir dari setengah dari responden yang sering

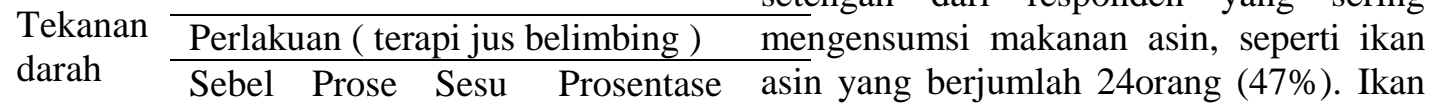

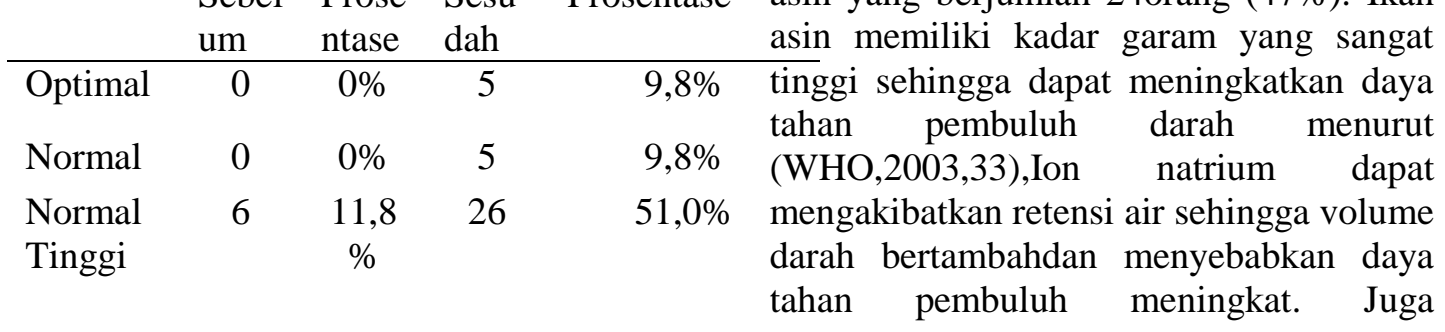


memperkuat

noradrenalin.

Tekanan darah sesudah dilakukan terapi jus belimbing

Tabel 10 didapatkan bahwa sebagian besar dari responden mengalami tekanan darah normal tinggi yaitu sebanyak 26 orang $(51,0 \%)$.

Peneliti berpendapat, tekanan darah pada penderita hipertensi berkurang karena penderita hipertensi di berikan terapi jus belimbing yang mengandung berbagai bahan yang dapa menunrunkan tingkat tekanan darah, dan adanya keinginan yang kuat untuk melakukan terapi.

Sesuai pernyataan apabila seseorang mengalami gangguankesehatannya maka mereka akan mencari informasi sebanyak-banyaknya (Townsend, 2010, 44).

Pengaruh terapi rendam kaki air hangat terhadap penurunan tekanan darah pada penderita hipertensi

Sebelum diberikan terapi jus belimbing hipertensi ringan sebanyak 28 responden (54,9\%). Dan setelah diberikan terapi jus belimbing selama 7 hari responden mengalami tekanan darah normal tinggi sebanyak 26 responden $(51,0 \%)$.

Sesudah di berikan terapi jus belimbing terdapat pengaruh terhadap penurunan tekanan darah.Hal ini dapat dilihat dari hasil lembar observasi setelah dilakukan terapi jus belimbing yang terdapat penurunan tekanan darah secara signifikan. Setelah dilakukan analisa menggunakan uji Wilcoxon signed rank test, didapatkan $P=(0,000)$ $<0,05$ yang berarti ada pengaruh terapi jus belimbing terhadap penurunan tekanan darah pada penderita hipertensi.

Peneliti berpendapat tentang adanya pengaruh yang diberikan jus beliming terhadap penurunan hipertensi tidak lain karena adanya kandungan yang terdapay pada buah belimbing.

Belimbing memiliki kandungan antidiuretik memiliki efek antihipertensi (Kartikasari, 2012, 39).

\section{KESIMPULAN DAN SARAN}

\section{Kesimpulan}

1. Sebelum diberikan terapi Jus belimbing, setengah dari responden mengalami Tekanan Darah hipertensi ringan.

2. setelah diberikan terapi jus belimbing selama 7 hari responden mengalami tekanan darah normal tinggi.

3. Pengaruh Jus Belimbing Terhadap Peurunan Tekanan Darah Penderita Hipertensi.

\section{Saran}

1. Bagi responden

Memberikan alternatif penanganan Tekanan Darah dengan jus belimbing tidak memberikan efek samping yang berbahaya bagi tubuh.

2. Bagi puskesmas

Petugas penyuluh kesehehatan untuk membantu unit kesehatan mensosialisasikan tentang pemberian Jus belimbing untuk menurunkan tekanan darah selain menggunakan obat-obatan.

3. Bagi peneliti selanjutnya 
Melakukan penelitian tentang faktor lain yang berhubungan dengan jus belimbing terutama faktor yang mempengaruhi jus belimbing harus diberikan lebih dari 7 hari.

\section{DAFTAR PUSTAKA}

Astawan. 2009. Sehat dengan buah. Jakarta: Dian Rakyat.

Kartikasari, Erni. 2012. Pengaruh Mengkonsumsi Buah Belimbing Manis (Averrhoa Carambola L.) Dan Buah Pepaya (Carica Papaya L.) Terhadap Jumlah Koloni Streptococcus Sp. Dalam Saliva Anak Usia 10 - 12 Tahun

Kementerian Kesehatan Repubulik Indonesia. 2013 . Riset Kesehatan Dasar (RISKESDAS). Jakarta: Institusi.

Notoatmodjo, S. 2010. Metodologi penelitian kesehatan. Jakarta : PT Rineka cipta.

Sugiyono. 2011. Metode Penelitian

Kuantitatif, Kualitatif, dan R\&D. Bandung : CV AFABETA.

Townsend, Raymond R. 2010. 100 Tanya Jawab Soal Hipertensi. Jakarta: PT Indeks.

World Health Organization (WHO). 2003.A global brief on hypertension: silent killer, global public health crisis. Geneva: WHO. 